\title{
De arrepiar: a musicista piauiense Gislene Danielle e suas artes - canto, interpretação, docência
}

\author{
Chilling: Piaui musician Gislene Danielle and her arts - \\ singing, interpretation, teaching
}

MARCIA PEREIRA DE OLIVEIRA(D) 1

\section{RESUMO}

Esse trabalho dedica-se a narrar o percurso formativo da musicista negra Gislene Danielle e pretende contribuir com a História da Educação Musical. Procura-se registrar as influências da música e do teatro na vida da cantora, sua trajetória acadêmica, tanto quanto de que maneiras chegou à docência. As perguntas mobilizadoras deste ensaio foram: Como a artista foi apresentada aos estudos de música? Por que a professora decidiu estudar teatro? Quando e como se tornou docente? A partir da articulação entre minhas memórias e da artista, juntamente com as respostas obtidas em entrevistas concedidas pela cantora tanto em canais de televisão local quanto a mim, analisadas em cruzamento com imagens e notícias disponibilizadas na televisão, nas redes sociais e no acervo da musicista, atriz e professora, foi possível perceber a relevância das instituições públicas e privadas, organizações, congregações e, sobretudo, das redes de relacionamentos pessoais e profissionais, que, somadas a estudo e trabalho, possibilitaram que Gislene Danielle se destacasse nas artes musicais, cênicas e na docência.

Palavras-chave: História da Educação Musical. Formação. Viagens.

Abstract

This work is dedicated to narrating the training path of black musician Gislene Danielle and intends to contribute to the History of Music Education. We seek to register the influences of music and theater in the singer's life, her academic trajectory, as well as in what ways she arrived at teaching. The mobilizing questions for this essay were: How was the artist introduced to music studies? Why did the teacher decide to study theater? When and how did she become a teacher? Based on the articulation between my memories and that of the artist, together with the answers obtained in interviews granted by the singer both on local television channels and me, analyzed in conjunction with images and news made available on television, on social networks and in the actress, teacher and musician's collection, it was possible to perceive the relevance of public and private institutions, organizations, congregations and, above all, the networks of personal and professional relationships, which, added to study and work, allowed Gislene Danielle to stand out in the musical, scenic and teaching arts.

Keywords: History of Music Education. Training. Trips.

\section{Resumen}

Este trabajo está dedicado a narrar la trayectoria formativa de la música negra Gislene Danielle y pretende contribuir a la Historia de la Educación Musical. Buscamos registrar las influencias de la música y el teatro en la vida de la cantante, su trayectoria académica, así como las formas en que llegó a la docencia. Las preguntas movilizadoras para este ensayo fueron: ¿Cómo se

\footnotetext{
${ }^{1}$ Instituto Federal do Piauí, Teresina, Piauí, Brasil. E-mail: marcia.pereira33@yahoo.com.br ORCID: https://orcid.org/0000-0001-8910-0101
} 
introdujo al artista en los estudios musicales? ¿Por qué la profesora decidió estudiar teatro? ¿Cuándo y cómo ella se convirtió en profesora? A partir de la articulación entre mis recuerdos y el del artista, junto con las respuestas obtenidas en entrevistas concedidas por la cantante tanto en canales de televisión locales como para mí, analizadas en conjunto con imágenes y noticias puestas a disposición en televisión, en redes sociales y en el colección de la música, actriz y docente, se pudo percibir la relevancia de las instituciones públicas y privadas, organizaciones, congregaciones y, sobre todo, las redes de relaciones personales y profesionales, que, sumadas al estudio y al trabajo, permitieron a Gislene Danielle destacarse en las artes musicales, escénicas y en la docencia.

Palabras clave: Historia de la Educación Musical. Capacitación. Viajes.

\section{Introdução}

Aquele que não viajou, nada viu (BÂ, 2010)

A princípio, esse texto seria construído com alicerce em entrevistas apoiadas na História Oral enquanto técnica e metodologia. Contudo, dado o contexto pandêmico ocasionado pela disseminação do vírus da Covid19, agravado em março de 2020, as respostas ao roteiro de perguntas previamente elaborado foram enviadas e respondidas por meio digital, em arquivos de áudio e por escrito.

As repostas obtidas foram transcritas e articuladas com minhas memórias sobre a cantora vastamente conhecida na cidade de Teresina, com entrevistas concedidas pela musicista em canais de televisão locais, assim como com imagens e notícias da atriz, veiculadas na internet, em redes sociais e no canal pessoal da musicista.

Esse ensaio traz uma introdução na qual apresenta as intencionalidades que moveram a pesquisa e descreve a organização do trabalho, que foi organizado tomando por base o ano de 1987, início dos estudos em música de Gislene Danielle, chegando aos dias atuais (2021), quando a Professora se encontra em vigorosa atividade acadêmica no Doutorado em Educação na Universidade Federal do Piauí, com plena atuação artística e ativo exercício da docência.

O trabalho divide-se ainda, além da introdução, em uma primeira seção sobre a presença da música na vida da cantora; uma segunda seção, discorrendo sobre as contribuições do teatro para a formação da professora; uma terceira seção acerca da inserção e continuidade na docência durante o percurso acadêmico e profissional da artista; seguida da última parte, destinada às considerações finais. 


\section{Abrindo as cortinas}

Essa seção descreverá um pouco de quem é a musicista piauiense a partir de sua relação com a música. Altiva e pragmática, Gislene Danielle parece pisar com pés desnudos sobre pedras do caminho. De queixo erguido e ar distante, a soprano, atriz e professora aparenta estar sempre montada, pronta a entrar em cena e brilhar, seja qual seja o papel no qual precise atuar: musicista, mãe, mulher negra, professora, acadêmica.

Lembro-me com nitidez de quando vi Gislene atuando pela primeira vez - foi em um sábado ao cair da tarde, no auditório da Federação Espírita Piauiense, situada à Rua Olavo Bilac, centro de Teresina. Naquele dia, aproximadamente vinte anos atrás, fazia um calor intenso e desconfortável, o que me faz pensar que era setembro. A moça bem jovem, de calca jeans e camiseta, participava de uma reunião com o coral amador da instituição, o qual regia. Parecia brava e determinada a fazer aquilo funcionar. Saí antes de presenciar o resultado.

Posteriormente, soube notícias dela atuando como regente no coral de senhoras católicas da Igreja da Santíssima Trindade, localizada no bairro Primavera, onde ambas nascemos. Soube somente agora, ao pesquisar para esta narrativa, que o referido coral foi criado por inciativa de Dona Francisca, mãe da regente, e que os ensaios, inclusive, aconteciam na casa de ambas, segundo relatou Gislene.

No decorrer dos anos, como a artista era figura presente na arte piauiense, assisti muitas de suas apresentações junto à Orquestra Sinfônica de Teresina - OST, na Igreja de Nossa Senhora do Amparo, no adro da Igreja São Benedito, na Igreja da Vila Operária, no Palácio da Música, e no Teatro 4 de Setembro.

Somente no natal de 2018, em uma festa particular da qual ambas éramos convidadas, a vi e ouvi cantar mais de perto. No ano seguinte, passamos a integrar o Núcleo de Pesquisa em Educação, História e Ensino da Música- NEHEMus, ambiente que agora permite esse "abrir de cortinas" para pesquisar e escrever sobre as artes e outros percursos que constituíram e constituem a trajetória da musicista piauiense.

Faço esses relatos iniciais para dizer que, em muitos momentos, estive nos mesmos espaços em que a intérprete atuou, e a memória me falha sobre datas, locais, 
nomes dos espetáculos em que pude usufruir de suas performances, mas algumas lembranças permanecem indeléveis: um vestido longo de lamê verde que Gislene usou em uma apresentação no Teatro 4 de Setembro, seu ar blasé, e a mais tocante das recordações - sua voz de arrepiar!

\title{
Acordes (nem sempre harmônicos)
}

Em 1987, ainda criança, a cantora iniciou seus estudos de Teoria Musical na Escola de Música de Teresina - EMT. Conforme a musicista, no período de seu ingresso, quando tinha onze anos, a Escola de Música divulgava seus cursos em rádio e televisão, o que interessou sua irmã - Maria Helena, que decidiu matricular-se. A mãe das meninas, Francisca Alves, então disse à irmã mais velha que levasse Gislene também. Sobre a Escola de Música, a soprano narrou, quando questionada para esse trabalho, que

\begin{abstract}
...das memórias que eu tenho é da gente lá, fazendo a matrícula, e era uma casa linda, eu gostei muito daquela casa, a arquitetura dela, na Pires de Castro, já era a segunda casa da Escola, não peguei a primeira casa e esse termo casa é muito usado [...]e para quem estava chegando na Escola de Música o fato de ser uma casa de música fazia muita diferença psicologicamente em como a gente entendia aquele ambiente. Na primeira sala tinha um balcão onde a gente pegava as informações e na sala ao lado já tinha um piano, se não me engano, um piano de cauda...então suas impressões quando você chega numa escola de música pela primeira vez e você já vê um piano de cauda [...] isso já me despertou uma vontade de estar lá, inclusive eu queria aprender a tocar piano (CARVALHO, 2020).
\end{abstract}

Esse depoimento corrobora outra entrevista concedida pela educadora musical citada em Silva (2020, p.40): “o prédio na [rua] Pires de Castro [...] era uma casa de música. [...] a gente chegava, na hora que você botava o pé na escola, tinha gente tocando pra todo lado". Tais memórias demonstram a duradora relação da cantora com a Escola de Música, local no qual começou seus estudos em música e de onde hoje é professora.

Deste primeiro encontro com a música, a cantora seguiu estudando. Além do curso de Teoria Musical, com início em 1987 até 1989, realizou de 1987 a 1994 a formação em Flauta Doce completo, ambos na Escola de Música de Teresina - EMT. Em 1995, participou do curso de otimização vocal junto ao Madrigal Vox Populi MVP', e do curso de Canto Lírico na Fundação Cultural Monsenhor Chaves - FMC, em 2007.

\footnotetext{
${ }^{1}$ O Madrigal Vox Populi, fundado em 9 de maio de 1988, é um Grupo Coral independente que tem objetivo de difundir o canto coral a todo tipo de público. Disponível em: https://www.ufpi.br/ultimas-noticiasufpi/7336-ufpi-convida-para-concerto-natalino Acesso em: 26 jun. 2020.
} 
Conforme relatou, quando começou a estudar canto lírico não havia professor da área em Teresina. Assim, a estudante de música, em busca de aprimoramento, viveu experiências de formação fora do Estado. Contudo, não recebeu suportes institucionais ou econômicos. Deste modo, embora as viagens tenham sido muito dispendiosas financeiramente, sua vontade de aprender fez com que as custeasse com recursos próprios. Pois, embora muito jovem à época, já trabalhava e também contava com o apoio familiar. Assim, informou que

A minha vontade de aprender me impulsionou a viajar para fazer cursos de férias, então fui para Londrina, para Fortaleza, Recife[...]e nessa época era interessante porque todo lugar que eu chegava as pessoas estavam dentro de cursos de música, ou estudavam em conservatórios ou faziam cursos de nível superior. Tinham professores de canto, que era uma coisa que para mim e para as outras pessoas que vivenciavam comigo aquela experiência aqui em Teresina, isso não era possível (CARVALHO, 2020).

Esteve no Paraná em 1998. O deslocamento foi para estudar canto e se apresentar na $17^{\mathrm{a}}$ Edição do Festival de Música de Londrina ${ }^{2}$. Em relação a essa viagem, Gislene destacou algumas particularidades: o fato de ter sido a primeira vez em que andou de avião e que viajou sozinha, pois estava com Lúcia Alvino³, mas sem o acompanhamento e supervisão de familiares. Também participou de cursos de extensão em canto nos anos de 2001 e 2002, respectivamente, realizados na Universidade Católica de Pernambuco - UNICAP. Citou também viagens de estudo à Fortaleza e Campina Grande.

A relação com a música se consolidou ao longo do tempo. Entretanto, foi causa de incertezas durante anos, pois tinha dúvidas se abraçaria esta arte como profissão. Gislene narra assim esta travessia: "passei muitos anos pulando de um curso para o outro sem me definir para trabalhar com música. Demorei muito para entender que a música podia ser algo profissional". Academicamente, iniciou diversos cursos, tais como Licenciatura em Letras, Biologia, Psicologia, Pedagogia e Educação Artística, mas graduou-se em Licenciatura em Música.

A acadêmica, hoje doutoranda em Educação, descreve a música como sendo "aquela parceira pra vida inteira, que trouxe pra mim essa estabilidade, essa certeza de que estou fazendo a coisa certa”. Relatou ainda que só quando estudou música na

\footnotetext{
2 Para saber mais sobre este evento: https://www.folhadelondrina.com.br/folha-2/tudo-em-nome-dacultura-32678.html. Acesso em: 26 jun. 2020.

3 Cantora Lírica piauiense. Professora de Técnica Vocal e Canto. Mais informações em: http://lattes.cnpq.br/1805895915258141. Acesso em: 26 jun. 2020.
} 
universidade, quando se formou, conseguiu finalmente se entender e ver qual era sua real função no mundo.

\section{Mulheres como espelhos}

Durante esse percurso de dúvidas, seguiam as apresentações, e a musicista construía laços e redes. A partir da Escola de Música de Teresina, das exposições públicas, das viagens, dos corais que Gislene regeu, aconteceram inspirações e convites. Desta forma, consideramos válido falar sobre pessoas que participaram da construção da carreira que a cantora foi lapidando e burilando até ser quem é hoje. A seguir, algumas mulheres ${ }^{4}$ que fizeram parte desse percurso.

Os estudos na Escola de Música de Teresina - EMT, como dito antes, se iniciaram por iniciativa da irmã mais velha de Gislene, Maria Helena, com estímulo de dona Francisca, mãe das duas meninas. $\mathrm{Na}$ "casa de música", outras inspirações femininas se fizeram presentes. A cantora lírica lembra que foi em um recital da Escola de Música que viu e ouviu Maristela Gruber ${ }^{5}$ cantando a primeira vez. Narrou assim o momento:

Maristela cantou as bachianas ${ }^{6}[\ldots]$ Ver a Maristela naquele palco, a Maristela tem uma sedução que ela trabalha no palco que fica todo mundo muito encantado, ela é uma mulher muito bonita, mas vai muito além disso. Ver aquela mulher cantando naquele palco me estimulou a querer também um dia cantar daquela forma (CARVALHO, 2020).

Outras referências femininas citadas foram as professoras de canto Mirna Rubin ${ }^{7}$ e Lucia Alvino. Conforme a soprano, a Professora Mirna esteve em Teresina ministrando um curso e nessa oportunidade Gislene disse que aprendeu a buscar a excelência. Com Lucia, a cantora lírica disse ter ganho uma experiência muito boa em técnica vocal.

\footnotetext{
${ }^{4}$ Uma observação da cantora que me chamou a atenção foi o fato de que, neste mesmo período, década de 1990, foi um momento em que os professores estavam indo embora de Teresina. Talvez por essa razão tão poucas influências masculinas, tendo sido citado somente o Maestro Aurélio de Melo.

${ }^{5}$ Cantora lírica mineira, viveu no Piauí, onde ministrou aulas de canto e piano na Escola de Música de Teresina, durante 14 anos. Disponível em: http://www.cultura.pi.gov.br/maristela-gruber-ministra-oficina-de-canto-em-teresina/. Acesso em: 11 jul. 2020.

${ }^{6}$ Bachianas é referência a obra de Villa-Lobos, composta de combinações étnicas brasileiras com a técnica de Bach, compositor predileto do músico brasileiro. Disponível em: https://filarmonica.art.br/educacional/obras-ecompositores/obra/bachianas-brasileiras. Acesso em: 11 jul. 2020.

${ }^{7}$ Ex-professora de canto da Universidade Federal do Estado do Rio de Janeiro (UNIRIO) e Doutora em voice perfomance. Disponível em https://www.mirnarubim.com.br/. Acesso em: 11 jul. 2020.
} 
Luiza Miranda ${ }^{8}$ e as irmãs da então coralista e hoje professora de teatro são a única referência de mulheres negras mencionadas como inspiração. Gislene conheceu Luiza no coral da EMT e disse sobre ela: " eu achava Luiza fascinante e ainda hoje acho...achava ela fascinante porque ela era muito alta e ficava imaginando que eu queria ser alta também daquele jeito...”

Outra mulher que influenciou a trajetória da soprano foi a neurologista Anita Pacheco. Essa relação não se implicava de maneira direta com a música, mas trouxe expressiva influência na vida da artista, pois, conforme relatado pela cantora, a médica foi responsável por diagnosticar o transtorno de déficit de atenção que a acometia. Em certa medida, o diagnóstico parece ter trazido o entendimento e a descoberta de questões sobre si, que veio a elaborar posteriormente, também com o auxílio do teatro.

\section{Entre máscaras e holofotes}

Essa parte do trabalho foi dedicada a tratar de como o teatro passou a ser parte da vida da cantora lírica. Em setembro de 2016, o programa televisivo Cena Aberta ${ }^{9}$ abre com a imagem e voz de Gislene Danielle cantando junto à Orquestra Sinfônica de Teresina. A artista, com partituras diante de si, em frente do público e das câmeras, soa como se ali fosse seu lugar de rotina, parece confortável e à vontade. Mas nem sempre foi assim, como a atriz relatou no referido programa, em entrevista concedida à jornalista Alexandra Teodoro:

Quando eu comecei a cantar, vi que eu não tinha coragem de enfrentar o público com firmeza, então comecei a pensar em como eu podia fazer, aí alguém disse: olha, o teatro é bom. Aí eu fui pra oficina de teatro Procópio Ferreira com o Luciano Brandão, e daí eu comecei a estudar teatro (CARVALHO, 2019).

Nesse mesmo sentido a ouvi sobre suas performances como atriz e início dessa nova forma de estar no palco, quando e por que essa outra arte foi incorporada em suas vivências. Entendi que, junto com as viagens, o ingresso no teatro talvez tenha sido um dos passos efetivos rumo à consolidação da carreira da atriz como cantora e como professora. A inserção no campo da interpretação parece ter contribuído para

\footnotetext{
${ }^{8}$ A cantora Luiza Miranda é Professora na Escola de Teatro Gomes Campos, compõe o grupo Ensaio Vocal, de Teresina. Integrou o "Madrigal Vox Populli" e atua na música piauiense há aproximadamente 30 anos. Disponível em: https://www.geleiatotal.com.br/2018/10/16/luiza-miranda/. Acesso em: 10 jul. 2020.

${ }^{9}$ Disponível em: https://www.youtube.com/watch?v=zTpDYVDuB4E. Acesso em: 10 jul. 2020.
} 
elevar sua capacidade de administrar suas relações interpessoais e para compreender suas subjetividades.

\title{
Autoimagem
}

O teatro foi, conforme a soprano, uma das experiências relevantes que a música lhe possibilitou vivenciar. A música exigia apresentações, ir para o palco, e já na primeira viagem, em 1998, começou a ver que não se sentia à vontade em cantar para as pessoas. Sobre isso, Gislene contou que "vinha toda uma série de coisas que me acompanhavam e que me atrapalhavam nessa coisa de ser tímida: eu usava óculos, meu cabelo eu achava que era feio..." Sobre essa relação da mulher negra com o cabelo afro, Berth (2019) infere:

\begin{abstract}
Nossos cabelos tornam-se, desde muito cedo um fardo difícil que, ao longo do nosso crescimento e desenvolvimento físico, vai pesando cada vez mais e abala a percepção de nossa identidade, pois independente de nossas escolhas estéticas e dos cuidados que temos com eles, os preconceitos raciais, estereótipos e clichês que foram implantados com a finalidade de ridicularizar esse atributo permanecem solidificados no senso comum da opinião pública e necessitam de um árduo trabalho de ressignificação para liberar mulheres negras dessas estratégias de desqualificação da estética negra (BERTH, 2019).
\end{abstract}

A partir da percepção de si e da necessidade de superar a timidez, achou que o teatro poderia ajudá-la. Foi então a oficina Procópio Ferreira, no Teatro 4 de Setembro, que, de acordo com as palavras da cantora, abriu a mente. Para ilustrar, apresento três momentos retirados do acervo pessoal da atriz e cantora em performances:

Figura 1 - Imagens de performance da artista: a. Maria Madalena em Jesus Cristo Superstar; b. Ardor, Amor; c. A hora do Angelus.
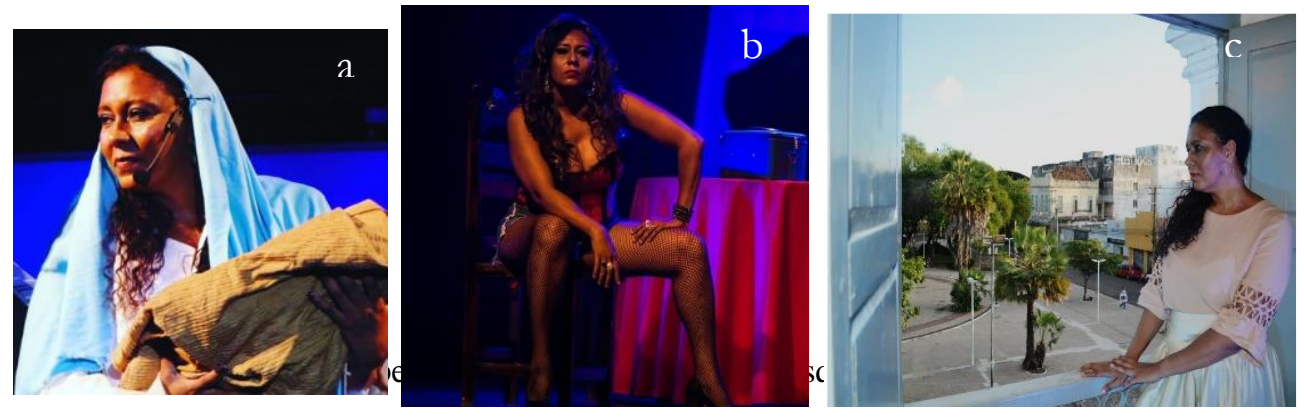

As imagens acima, articuladas com as entrevistas da cantora para a televisão, juntamente com as respostas do roteiro enviado por mim e combinadas com os diversos vídeos de diversas apresentações da cantora, levaram-me a concordar que “as pessoas da pessoa são numerosas no interior da pessoa” (BÂ, 2010), tamanha a 
complexidade que envolve os processos de subjetivação de cada um, a partir de suas relações e experiências vividas. Assim, a menina, antes tímida, construiu a mulher que afirmou:

Foi o teatro que me deu possibilidade de pegar essa música que já estava dentro de mim e levar para o palco de maneira deliciosa, de uma maneira em que posso cantar, posso brincar e posso sentir o prazer que é ter as pessoas olhando pra mim enquanto eu estou cantando [...] essa experiência do palco é gigantesca. Todas as vezes que eu subo no palco, eu faço um ritual de agradecimento e peço que eu seja um instrumento (CARVALHO, 2020).

\section{Questões de cor(?)}

A artista é incisiva sobre como deseja trabalhar suas artes: o que quer é emocionar pessoas. Assim, não obstante a vontade de ser um instrumento, ao ser convidada a adentrar em questões como o preconceito, optou por não empunhar bandeiras diretamente. Em se tratando de racismo e representatividade, por exemplo, colocou:

Eu me lembro que quando eu era criança foi muito difícil eu entender que eu era preta, muito difícil [...]demorou um tempo para eu entender qual era a raça que eu pertencia e depois muito mais tempo para eu ir tirando todas as coisas que já tinham jogado em cima de mim de que isso é ruim, que isso o é feio.

Nesse sentido, colocou que, apesar de ter consciência de como as coisas são (Brasil, país racista), afirmou não gostar da militância vinte e quatro horas, pois, para a musicista, a questão não se encerra em gostar de pessoas negras/pretas ou não, mas de lhes dar ou de não lhes negar espaço para que atuem.

Gislene relatou que embora "sim, veja, reconheça, vivencie essa questão do racismo em várias situações, não vivencio tanto quanto outros colegas" (CARVALHO, 2020) e, em parte, atribui esse não sofrer preconceito ao fato de já ter uma carreira na música, embora perceba que, em termos de visibilidade, "como cantora lírica, uma cantora branca, mesmo que cante pior, mesmo que desafine, terá mais projeção por ser branca" (CARVALHO, 2020). Isso, segundo Gislene, faz diferença na música. Na academia e na docência não sentiu esse tratamento diferenciado. 
Ainda sobre o assunto, lembrou-se de ter ouvido no Mestrado que racismo não é uma questão de afeto, mas de poder. Nessa direção, Boakari (2019) reflete que a necessidade dessa demarcação de poder resulta de vestígios do colonialismo, base para "racismos, machismos, sexismos,[...] homofobias" (ALVES; BOAKARI; SILVA, 2019).

A soprano acredita que o preconceito no Brasil está associado mais à questão econômica. Assim, crê que "a questão de ser negro ou não ser negro não faz tanta diferença, faz muita diferença é ter dinheiro ou não" (CARVALHO, 2020). Afirmou sentir que, se fosse rica, mesmo sendo negra, pelo menos em sua frente não seria tratada com diferença, não notaria situações de racismo e a cor da pele não importaria.

\title{
Harmonização
}

Nessa terceira etapa do ensaio, o assunto é a docência, e como se harmonizaram a cantora lírica, atriz, professora e acadêmica. Neste trabalho, fiz a opção de externar que compreendo a docência como uma arte, e das mais delicadas. Desta forma, quis saber como a artista Gislene Danielle incorporou, em suas experiências, mais esta atividade, e assim foi o relato:

\begin{abstract}
A docência começou a princípio de uma forma bem inusitada. Quando eu estava na escola de música, acho que eu tinha uns vinte anos e houve um tempo na escola de música em que comecei a dar aula porque eu já tinha feito o curso e um ex-aluno poderia dar aula, aí nessa época não tinha um rigor para dar aula lá. Porque assim, houve vários momentos: quando eu estudei os professores eram muito bons, e de tão bons, preocupados com suas formações não ficaram aqui, foram embora daqui (CARVALHO, 2020).
\end{abstract}

Esse comentário levou-me a refletir juntamente com Nunes (2017), quando este se refere a Teresina como “[...] uma cidade que trata mal os próprios filhos, que os expulsa, que insiste em não reconhecer os vivos [...] c cidade que não conhece seus escritores, seus músicos [...] a cidade que não consome sua arte” (NUNES, 2017, p. 17).

Nesse sentido, Gislene também havia comentado que, nesse período de emigrações, sempre que viajava se deparava com a surpresa das pessoas de fora ao saber que aqui se estudava e produzia música erudita. Surpresa a qual ela respondia: "sim, somos do Piauí e fazemos um bom trabalho lá". A cantora acredita que foi 
também nesse tempo de muitas partidas que o Maestro Aurélio de Melo, que já atuava na EMT, firmou o propósito de, mesmo sendo um dos bons, ficar e aqui produzir.

No entanto, esse princípio na docência também teve outros caminhos. Em 1993, o irmão mais velho de Gislene faleceu em um acidente de moto. Em razão desta perda familiar, a então ex-aluna, e professora da EMT, interessou-se pela Doutrina Espírita que lhe foi apresentada por uma colega de flauta doce. Passou a frequentar a Federação Espírita Piauiense e lá recebeu o convite para reger o coral federativo, o que, para a regente, foi uma atividade docente. Nesta ocasião a conheci, como citei na primeira seção deste trabalho.

\section{De nota em nota}

Os passos de Gislene na docência, como nas outras duas artes - música e teatro, não aconteceram de uma hora para outra, nem ocorreram sem talento, trabalho ou apoio. Houve um encadeamento de acontecimentos, escolhas e relações que possibilitaram uma caminhada nem sempre linear, mas ascendente.

Fazer parte desde criança de uma instituição de ensino musical expressiva na cidade foi uma dessas escolhas. Frequentar os lugares em que a cena musical acontecia, aliados a estudo e trabalho, trouxeram oportunidades que não foram fruto do acaso, mas construções que tiveram resultados. Sobre essa sucessão de acontecimentos, Gislene deu continuidade à narrativa sobre seu ingresso na docência:

Já cantava em coral há muito tempo, comecei a cantar com 11 anos, então aceitei reger o coral da Federação Espírita. Tempos depois fui convidada a reger o coral da Igreja de Fátima. Na Igreja de Fátima era um pessoal bem mais elitizado, então uma advogada me convidou para reger o coral na missa de aniversário de 15 anos da filha dela, que estudava no Colégio das Irmãs. Nisso as irmãs me viram e me convidaram para dar aula no Colégio das Irmãs e ao mesmo tempo no Madre Savina. Foi um convite atrás do outro em um período bem pequeno (CARVALHO, 2020).

Entretanto, o exercício da docência naquele período trazia desconforto, pois a então professora iniciante se sentia sem base. À época era estudante de psicologia e lhe trazia inquietação não ser formada em música e, segundo ela, "isso é que me empurra, depois, anos depois, para estudar música na universidade" (CARVALHO, 2020). 
A docência, conforme a professora, só se torna algo prazeroso após a Licenciatura em Música. Em 2013, acontece o retorno à Escola de Música via processo seletivo, quando assume como professora substituta, para dar aula de canto. Em 2015, enquanto acadêmica de música, vai estagiar no Instituto Dom Barreto IDB.

No IDB, ouviu da Professora Marcia Rangel, coordenadora pedagógica do Insitituto, a seguinte frase: "olhe para as crianças, observando as crianças você vai aprender o que não aprenderá em nenhuma universidade”. Segundo Gislene, essa experiência com a coordenadora pedagógica, juntamente com a Licenciatura na UFPI, foi o que fez com que realmente se apaixonasse pela docência, pois, conforme disse:

\footnotetext{
Nesse tempo todo eu dei aula, dei aula particular, aula de canto, regi corais, mas a consciência é recente. Tudo isso foi um exercício, mas a consolidação desse exercício como algo que eu queria fazer como profissão só ocorreu quando eu estava na UFPI e comecei a fazer os estágios no Dom Barreto (CARVALHO, 2020).
}

Após a graduação em música e a (re)descoberta da docência, a artista ingressa no Mestrado em Educação da Universidade Federal do Piauí e posteriormente no Doutorado, sob a orientação do Professor Ednardo Monteiro Gonzaga do Monti. Atualmente, faz uma segunda Licenciatura em Pedagogia, permanece no Colégio Dom Barreto, é Professora substituta da UFPI, da EMT e está aprovada em concurso público para Professora efetiva da Prefeitura Municipal de Teresina.

\section{Considerações finais}

O que é possível inferir sobre este trabalho é que busquei deixar o registro, para a História da Educação Musical, do percurso de uma musicista negra, que encontrou nas artes várias formas de expressão de sua existência elaborada ato a ato. Penso que essa trajetória, permeada de espaços e relações, deixa o refletir sobre o valor da caminhada, de cada passo da jornada.

Foi possível notar, em cada passo proposto, seja na música, no teatro ou na docência, que não se anda sozinho e, por mais que o lapidar interno seja individual, nem mesmo esse polimento interior se dá sem as relações, ou seja, não se avança só, sem suporte. 
As políticas, instituições públicas e privadas, organizações (Escola de Música de Teresina; Universidade Federal do Piauí, Instituto Dom Barreto, Colégio das Irmãs, Madre Savina, Orquestra Sinfônica de Teresina - OST); as congregações (Federação Espírita Piauiense, Igreja de Fátima, Igreja da Santíssima Trindade), sobretudo as pessoas (mãe, irmã e todas as mulheres espelho, orientadores de Graduação, Mestrado e Doutorado), fizeram e fazem parte desse construto chamado de trajetória que segue sendo somado ao trabalho e estudo da cantora que traz lume a estes escritos.

Escrever esse trabalho trouxe uma percepção adicional: com a emergência das tecnologias que tudo medeiam, diante do imediatismo que nos assola, seja qual seja o olhar apressado, foi bom perceber que realizações sólidas levam tempo, carecem de amadurecimento, esforço, paciência.

Ademais, em tempos feitos de instantâneos e relações descartáveis, é bom sentir perenidade e que equilíbrio não necessariamente vem em retas e metas, mas que pode chegar apesar das sinuosidades das travessias.

\section{Referências}

ALVES, R. D. S. A.; BOAKARI, F. M; SILVA, F. B. "Síndrome da luta maior": um perigo para a educação anti-discriminatória. Educação e Cultura Contemporânea. v. 16, p. 348-372, 2019.

BÃ, A. H. A tradição viva. In: KI-ZERBO, J. (org.). História Geral da África I. São Paulo: Ática, v. I, 2010. p. 181-218.

CARVAlHO, G. D. Depoimento a Márcia Pereira de Oliveira. Teresina: Meio digital, 2020.

BERTH, J. Empoderamento. São Paulo: Pólen, 2019.

MONTI, E. M. G. Afetividades e (auto) censura na escrita autobiográfica da pianista Magdalena Tagliaferro. Revista Eletrônica Documento/Monumento, v. 1, p. 72-83, 2018.

NUNES, A. S. Ressuscito na cidade suicida. Teresina: Desenredo, 2017.

SILVA, J. P. Casa de Sons - Escola de Música de Teresina (1981-1991): sujeitos e práticas educativas entre salas e palcos. 2020. Dissertação (Mestrado em Educação) - Centro de Ciências da Educação. Universidade Federal do Piauí, Teresina, 2020 